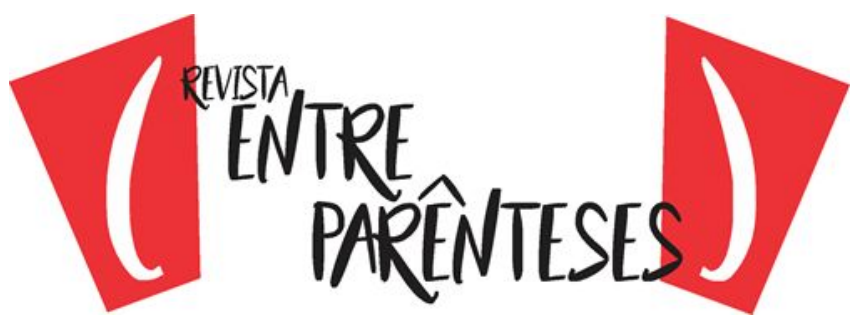

RESENHA

\section{PARA OUVIR O CANTO DAS SEREIAS: UM COMENTÁRIO SOBRE A HISTÓRIA INCOMPLETA DE BRENDA E DE OUTRAS MULHERES (2016)}

LUDERMIR, C. A história incompleta de Brenda e de outras mulheres. Rio de Janeiro: Confraria do Vento, 2016. (ISBN 978-85-5532-026-2)

Luiz Henrique Moreira Soares ${ }^{1}$

Universidade Estadual Paulista "Júlio de Mesquita Filho" (UNESP/lbilce) - CNPq

(luizhsoares83@gmail.com)

Se o discurso é a coisa que habita o corpo, e o corpo é o lugar de toda a experiência, como contar, então, sobre a experiência do desejo e da violência em certos corpos? Quais experiências são tidas como possíveis e legítimas? Quem tem direito à narrativa, ao luto, à vida? Essas são algumas das questões que podem ser discutidas a partir da obra $A$ história incompleta de Brenda e de outras mulheres (2016), do escritor e jornalista pernambucano Chico Ludermir. Lançada pela Confraria do Vento, a obra é composta por onze contos sobre as vivências e experiências de mulheres trans e travestis da cidade de Recife. $O$ trabalho desenvolvido parte de mais de três anos de pesquisas e entrevistas com onze mulheres trans e travestis recifenses que tiveram suas histórias escritas, inscritas e contadas por Ludermir a partir de seus próprios relatos. Entre as narrativas, Ludermir acrescenta um ensaio fotográfico de cada uma das personagens, retratando, de forma delicada e complexa, cenas cotidianas dessas existências tão anônimas.

Mas trata-se muito mais do que um livro de contos, um livro de relatos, ou até mesmo um mero livro de fotografias: é uma metáfora da possibilidade de preencher os vazios, mas também de ressignificá-los - renomear ou simplesmente

\footnotetext{
${ }^{1}$ Mestrando do Programa de Pós-graduação em Letras (PPGL), da Universidade Estadual Paulista "Júlio de Mesquita Filho" (UNESP/ Ibilce) - Campus de São José do Rio Preto. Bolsista do Conselho Nacional de Desenvolvimento Científico e Tecnológico (CNPq).
} 


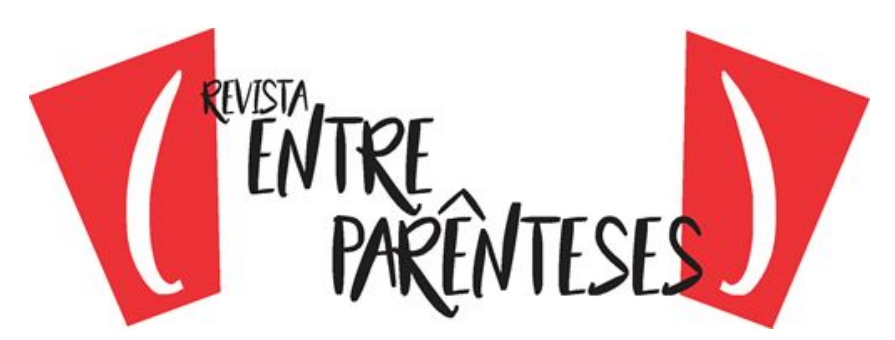

implodir. E é justamente da implosão que muitas das histórias contadas são constituídas. Permeadas por deslocamentos, vazios e silêncios, as histórias são atravessadas pela multiplicidade da existência particular de cada uma das personagens. Ao mesmo tempo, essas histórias também produzem uma existência concreta e real aos corpos que transitam pelas normas de gênero. $E$ por isso são caracterizadas como vidas que não "importam"; e por isso esses corpos habitam o espaço do "entre-lugar", na fronteira de um discurso social que dita o que é legitimamente humano. A questão da representação de alguns sujeitos na contemporaneidade, desse modo, perpassa por relações estabelecidas historicamente por estruturas discursivamente violentas. Pensar a atividade literária como parte integrante dessa estrutura é questionar a forma como o texto demarca o sujeito tido como feminino e o sujeito tido como masculino, além da construção simbólica que o gênero e a sexualidade adquirem no discurso literário. É no questionamento e na desconstrução das "verdades" sobre os corpos que se produz o rompimento com discursos essencialistas e possibilita, assim, uma reivindicação para outras vivências. Os contos de Ludermir, nesse sentido, produzem a dissidência: ao narrar a história de Luciana, mulher trans com mais de 60 anos que rememora os abusos e torturas sofridas por parte de policiais na época da Ditadura Militar, no conto "Noturno do Recife", o autor observa a forma como os corpos dessas mulheres são atravessados pelas violências e como suas humanidades são arrancadas - tal como o episódio em que um cachorro da polícia agarra a perna de Luciana, deixando-a em carne viva antes de ela ser levada à prisão por crime de "vadiagem". No conto "A mãe de Anne", o choro da personagem Anne se mistura ao mar - como a água salgada que dá brilho e cenário ao canto das sereias; como a água que envolve a criança no útero da mãe, antes de nascer. Com apenas dezesseis anos, Anne já aprendeu que é necessário ter muita coragem para não mais esconder as bonecas e ser o que realmente se é. 


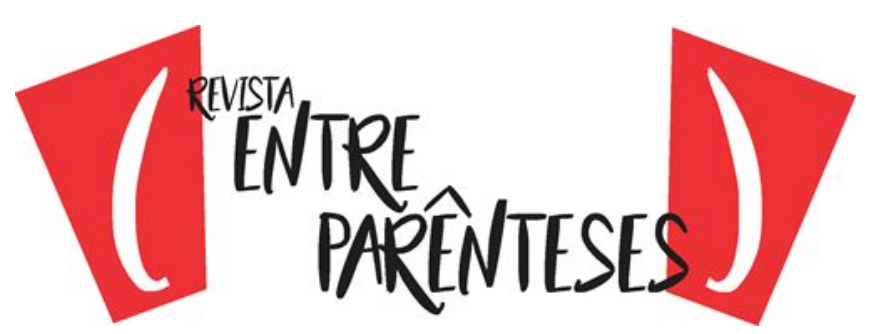

Já Christiane, personagem do conto "Portrait of a lady", a água salgada também tem gosto de desejo. A sua gravidez psicológica, o seu casamento de 25 anos com Mailson, a dor do parto que é sempre emocional, e o canto mudo no microfone - tudo isso se configura numa potência de uma feminilidade extremamente performática, mas sempre possível: "À medida que cresciam as notas, Chris arreganhava a boca pintada de batom, e se enchiam lágrimas os olhos. Se era fingimento ou não, era impossível saber." (LUDERMIR, 2016, p.56). Em "Não faz tanto tempo assim", o protagonismo é de Deusa: travesti que dá muita importância às perdas, porque estas estão estiradas na imensidão da incompletude - e também significam coisas. Ela mostra que quando se tem dezessete anos nada é antigo. Tudo ainda é muito vivo e recente. Por ter sua vida também construída nas violências e nas perdas, Deusa assume uma posição de coragem: "Cada arranhão, Deusa devolve ao mundo. Cada tapa, puxão de cabelo que levou, ela engole, digere e cospe. É aprendizado antigo, sobrevivência." (LUDERMIR, 2016, p.65). Além das perdas e das dores, a ausência é outra coisa que também atravessa a vida de Luana, personagem do conto "Nascer é muito comprido". É no colchão que guarda o formato exato dos corpos de Altair e Luana que se vê o entendimento de um sobre o outro - e a possibilidade de amar, de ser quem se é, de perceber e admitir que o desejo é muito maior do que termos técnicos e meramente essenciais como "mulher". Luana acredita que a linguagem tem suas dúvidas e angústias, por isso aceita. Aceita que Altair lhe escove os cabelos e lhe ajude a retirar os pelos do peito, queixo, sobrancelha, axila e bunda com uma pinça - isso possibilita, para ambos, uma experimentação de dor e intimidade extrema.

Já o que permeia o conto "A paixão de Rayane" é a reinvenção. A personagem Rayane, mulher trans e evangélica, encontra em Deus o seu refúgio: é nas brechas que ela produz as suas possibilidades de existência, rejeitando rótulos e essencialidades. Por sua vivência subjetiva, é crucificada todos os dias. Mas ela salva a humanidade e reivindica, também, o carinho e o afeto que é direito, além de 


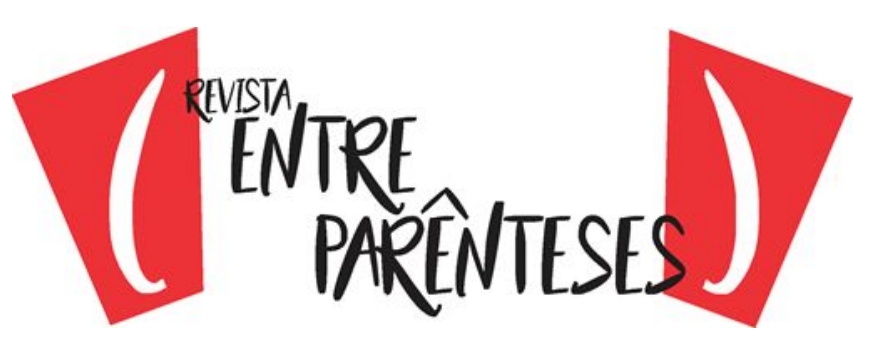

criar a sua própria forma de ser mulher e entender o amor. Há, ainda, existências anônimas que são ainda mais anônimas: essa é a história de Mariana, protagonista do conto "Existir é dar um jeito". Mesmo não tendo redes sociais, Mariana existe. Apesar de toda a inexistência construída sobre a sua figura, Mariana existe na complexidade com que enfrenta a vida, levando tiro ou apanhando do pai com um cipó arrancado de araçá. Mariana existe no silêncio das frases curtas, existe na sua forma de falar - triste e agressiva -, existe no cheiro cotidiano da exclusão. Existe porque enfrenta a inexistência todos os dias, um dia por vez. "Mariana não sabe mas saberá - que o encontro com ela foi a reafirmação da vida." (LUDERMIR, 2016, p.98)

E a existência é também construída de lembranças. Franncine é a protagonista do conto "O filho que deixou de ser" e sabe disso: sua vida foi feita de idas e vindas, voltas e encontros, perdas e ganhos, cicatrizes e coisas que se perderam no emaranhado das sensações. Aos trezes anos, filho deixou de ser - e passou a ser Franncine, experimentando as suas próprias formas de feminino. Franncine volta mulher - a filha voltou. Franncine, além de experimentar a sensação de ser mulher na sua própria complexidade, experimenta também o perdão - perdão e cuidado ao pai que a rejeitara durante toda a vida. Em "Formas de voltar para casa", Maria Clara habita os desejos dos sonhos escondidos. Para ser quem se é, a personagem enfrenta barreiras e desafios todos os dias. Gosta de estar em nenhum lugar, ambígua: e é nesse espaço que consegue transitar por onde bem entende, altiva, atravessando os caminhos e os limites de si mesma - a incompletude tem uma beleza que texto nenhum dará conta. Já para Wanessa, protagonista do conto "O corpo está de mudança", a vida é um constante deslocamento de coisas. Wanessa sabe que tem vezes que é preciso preencher vazios, e tem vezes que é necessário deixar como está. Morou em tantas casas que nem sabe, sempre de mudança. E a mudança continua: Wanessa fez-se e está se fazendo Wanessa, aos 


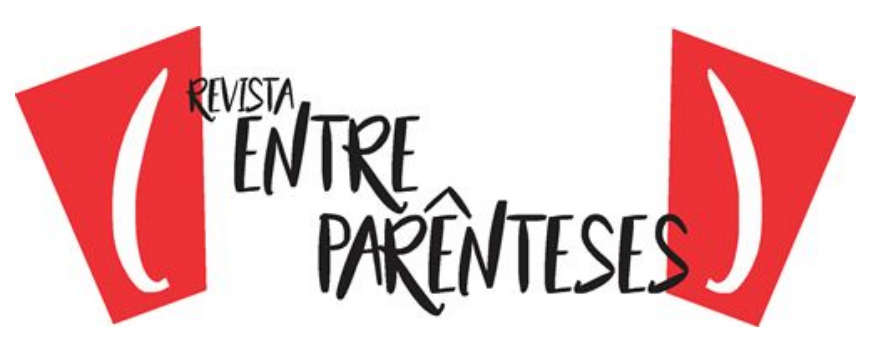

poucos, com uma insistência na liberdade e abandonando tudo aquilo que não pode levar consigo.

Brenda, antes de ser Brenda, era "um menino que chorava pelo avesso". Mas acontece que Brenda sempre foi Brenda - é que gestava esse nome dentro de si e as contrações doíam: uma hora teria de nascer. E ela nasceu e renasceu: abandona a carreira militar para viver a vida que é sua. E para isso enfrenta as chuvas de pedra dos meninos da escola, enfrenta o não-existir incômodo das violências, arrisca a vida para viver. A incompletude da história de Brenda é um silêncio no mar - atravessa o mar, então, como sereia, e encontra a si mesma do outro lado da margem.

As histórias incompletas dessas mulheres trans e travestis promovem a afirmação de feminilidades potentes, ao mesmo tempo em que questiona as formas como as identidades abjetas são entendidas e concebidas. De acordo com a professora e filósofa americana, Judith Butler, em seu livro Problemas de gênero: feminismo e subversão da identidade (1990), a partir da noção de "performatividade" na linguagem, é necessário propor uma desconstrução da dicotomia sexo/gênero. Para a autora, o gênero nada mais é do que uma categoria que dita normas regulatórias por meio de uma repetição ritualizada, que produz a (in)viabilidade da existência em corpos que fogem de tais normas. O gênero é, sobretudo, algo construído socialmente, no/pelo discurso, e pode ser entendido como uma categoria analítica da sociedade, pois organiza as desigualdades por meio das relações que estabelece:

A marca do gênero parece "qualificar" os corpos como corpos humanos; o bebê se humaniza no momento em que a pergunta 'menino ou menina?' é respondida. As imagens corporais que não se encaixam em nenhum desses gêneros ficam fora do humano, constituem a rigor o domínio do desumanizado e do objeto, em contraposição ao qual o próprio humano se estabelece. (BUTLER, 2003, p.162) 


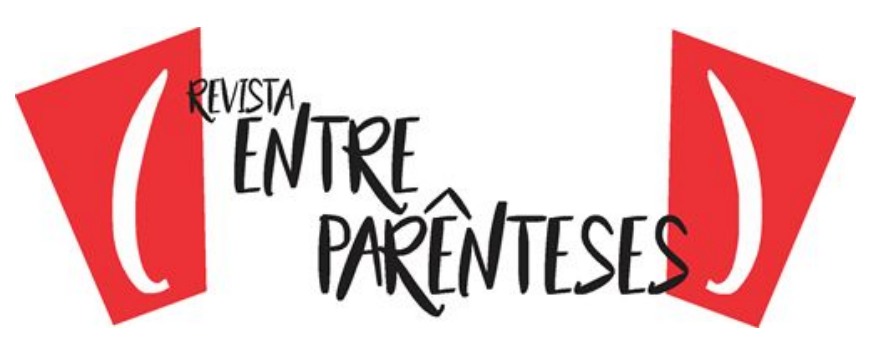

O caráter de abjeção desses corpos se estabelece no mesmo sentido em que são, também, corpos desprovidos de subjetividade: o "espaço de ser" é então negado a todos e todas que se impõem às necessidades de adequação a um gênero ou outro. Butler ainda afirma, no início do livro, que "o feminino já não parece uma noção estável, sendo seu significado tão problemático e errático quanto o de mulher" (BUTLER, 2003, p.9). Por parecerem categorias meramente estáveis, "mulher" e "feminino", assim como "homem" e "masculino", atuam no sentido do binarismo, atribuindo significados e realizando a manutenção das relações de poder existentes na sociedade. Segundo Cláudia Maria Ceneviva Nigro (2015), o território da ficção e da atividade literária é um desses espaços possíveis para se questionar e problematizar o discurso sobre o gênero. Para a autora:

(...) a ficção quebra os signos e artefatos do considerado essencial e os recompõe com a invenção, a fragmentação. Ao reavaliar os espaços ocupados pelo gênero na obra literária, reavaliam-se os papeis das personagens femininas/masculinas e cria-se o lugar para a ruptura. (NIGRO, 2015, p.16)

Assim, A história incompleta de Brenda e de outras mulheres produz a ruptura, no sentido de possibilitar o reconhecimento de vozes e vidas violentadas pelo discurso social. Brenda e as outras mulheres apropriam-se da posição de sujeito falante, invocam suas dores, memórias, amores e desejos como questões também importantes e vivíveis. Em outras palavras, a obra não apenas possibilita a reafirmação do corpo-discurso de cada uma das personagens-pessoas, mas constrói uma rede de afeto e alteridade com os leitores daquelas histórias, fazendo com que essas mulheres trans e travestis ocupem, por direito, o espaço do humano, do existente e do possível - em um processo de distanciamento e aproximação. Mas, o que seria de nossa existência, senão fosse a produção, o encontro e a fusão das nossas narrativas com as dos outros?

\section{Referências}




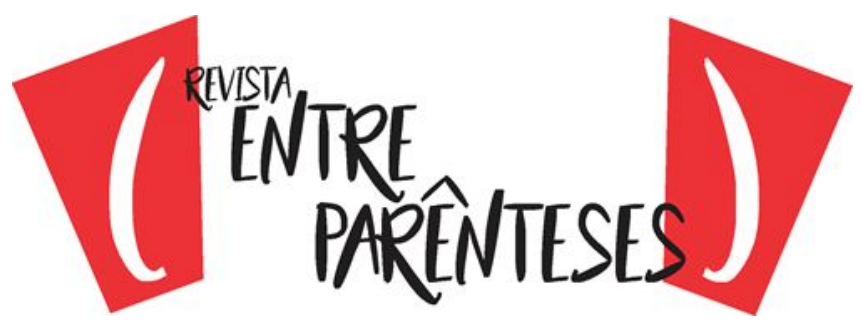

BUTLER, J. Problemas de gênero: feminismo e subversão da identidade. Rio de Janeiro: Civilização Brasileira, 2003.

NIGRO, C. M. C. Introdução. In: NIGRO, C. M. C.; CHATAGNIER, J. C. Literatura e gênero. São José do Rio Preto: HN Editora, 2015. p. 15-22. 